\title{
PERSPECTIVES
}

\section{Mentoring Faculty in Academic Medicine}

\author{
A New Paradigm? \\ Linda Pololi, MBBS, 'Sharon Knight, PhD, $R N^{2}$ \\ 'Women's Studies Research Center, Brandeis University, Waltham, Mass, USA; ${ }^{2}$ Department of Health Education and Promotion, College \\ of Health and Human Performance, East Carolina University, Greenville, NC, USA.
}

\begin{abstract}
In this paper, we discuss an alternative structure and a broader vision for mentoring of medical faculty. While there is recognition of the need for mentoring for professional advancement in academic medicine, there is a dearth of research on the process and outcomes of mentoring medical faculty. Supported by the literature and our experience with both formal dyadic and group peer mentoring programs as part of our federally funded National Center of Leadership in Academic Medicine, we assert that a group peer, collaborative mentoring model founded on principles of adult education is one that is likely to be an effective and predictably reliable form of mentoring for both women and men in academic medicine.
\end{abstract}

KEYWORDS: mentoring; faculty; academic medicine; collaborative peer group mentoring.

DOI: $10.1111 / \mathrm{j} .1525-1497.2005 .0167 . x$

J GEN INTERN MED 2005; 20:866-870.

$\mathrm{R}$ esearch on mentoring in academic medicine is limited, ${ }^{1}$ with great variation in how the concept of mentoring is defined $^{2-6}$ and with more attention paid to outcomes rather than the process of mentoring. One notable exception documents the process of effective mentoring by adopting a case study approach. ${ }^{7}$ Nationally, one-third ${ }^{1}$ to one-half ${ }^{8}$ of faculty report being mentored, but reported surveys neither differentiate informal from formal mentoring experiences, nor document the longevity of the mentoring process. Nevertheless, mentoring has been shown to contribute to an individual's career development in academic medicine and other fields, ${ }^{8-12}$ particularly in the areas of research, ${ }^{11,13}$ career satisfaction, ${ }^{1,11}$ and perceived institutional support. ${ }^{10,14}$ The mentoring process provides a means by which junior faculty can develop professional academic skills including career management, knowledge about academic medicine, and collegial networking. ${ }^{10,12}$ Mentoring in research and academic development may be particularly important to new medical faculty, who often find themselves inadequately prepared for academic careers. ${ }^{15,16}$

The changing nature of the current health care environment, increased clinical and administrative responsibilities, reductions in time and collegial support for scholarly activity ${ }^{17}$ and teaching, and a lack of access to mentors can hinder faculty scholarly productivity ${ }^{14}$ and career satisfaction ${ }^{8,13,18,19}$, and may result in attrition from academe ${ }^{20}$ Currently, $37 \%$ to $47 \%$ of physicians experience burnout. ${ }^{21-23}$ Effective mento-

The authors have no conflicts of interest to report.

Address correspondence and requests for reprints to Dr. Pololi: Women's Studies Research Center, Brandeis University, Epstein Building, Mail Stop 079, 515 South Street, Waltham, MA 02454-91 10 (e-mail: lpololi@brandeis.edu). ring may help faculty increase career satisfaction and productivity and reduce their risk for burn-out.

Dunnington's question, "Where have all the mentors gone?"24 resonates for many today in academic medicine. Recent changes in medicine are transforming clinical practice, research, education, and thus mentoring practices. Increased pressure to be "clinically productive" impacts negatively on the availability of mentors and their ultimate willingness to remain in academe. ${ }^{20,25,26}$ Potential mentors who are uncertain about what successful mentoring entails may be reluctant to take on the responsibility and have little access to mentor training.

A decline in the number of clinical research faculty and the consequent reduction in the availability of research mentors in academic medicine ${ }^{15,27}$ has resulted in fewer junior faculty who are well prepared as clinical researchers. ${ }^{15}$ Although a longstanding legacy of informal mentoring has served as a primary method of professional socialization for faculty in academic medicine, ${ }^{11,28}$ health care specialties that have traditionally focused on clinical practice and service face a dearth of senior mentors to assist junior faculty as academicians. ${ }^{9}$ In academic General Internal Medicine, for example, with only $11 \%$ of faculty as full professors, $21 \%$ at the associate professor, and $58 \%$ at the assistant professor levels (SJIM meeting 2003, Mentoring Precourse), it is unlikely that all junior faculty could be assigned a senior mentor. Additionally, a division chief may find conflict of interest in his or her roles as both guardian of the division and facilitator of a junior faculty member's professional aspirations. Thus, although senior faculty can and do make significant and valued contributions to the professional growth of junior faculty, such mentoring has become increasingly scarce.

The effective mentoring relationship facilitates the formulation and "realization of a person's own dream"29 through an evolution of personal growth and development. Rather than relying on a dyadic relationship, the mentoring paradigm that we propose is located in a group process characterized by nonhierarchical peer relationships, protégé(e) empowerment, and self-direction. This reflective process involves the self-identification of personal and professional goals that are consistent with an individual's personal values.

\section{TYPES OF DYADIC MENTORING: "INFORMAL" AND "FORMAL"}

The notion of a senior professional promoting the career of a junior protégé(e) ${ }^{13}$ has shaped the development of mentoring

Received for publication February 28, 2005

and in revised form March 22, 2005

Accepted for publication April 4, 2005 
programs to this day, and senior physicians have been expected to model desired behaviors and attitudes for their juniors. ${ }^{30}$ Most people equate mentoring with this traditional dyadic model. Informal mentoring occurs serendipitously when 2 individuals are drawn together by mutual interests and appeal, resulting in a kind of "spontaneous or accidental mentoring [that] almost always works." 31 This type of mentoring is characterized by a long-term, mutually satisfying relationship that is not initiated, managed, or structured by an institution or organization. ${ }^{32}$ Hallmarks of the relationship are support, mutual respect, and compatibility. ${ }^{33}$ Access to informal mentoring occurs only for a minority of particularly fortunate faculty and may be especially difficult to attain for those who tend to be marginalized, including women. ${ }^{34}$ Since women now have equal access to medical schools and currently comprise about a quarter of medical faculty, the issue of mentoring for women becomes critical for the profession. Mentoring has been suggested as a way of addressing women's lack of advancement in academic medicine. ${ }^{35}$

Although informal mentoring provides a more effective mentoring model, ${ }^{32}$ the recognition that many faculty lack mentors ${ }^{36,37}$ has led institutions to increasingly implement formal mentoring programs. Unlike informal mentoring, formal mentorship is planned, often institutionally supported or mandated, and is somewhat reminiscent of a "blind date" or "arranged marriage." ${ }^{32}$ It involves the assignment of a protégé(e) to a mentor, with the (often-unrealized) intention of somehow fostering the quality and kind of relationship seen in informal mentoring. ${ }^{31}$ Power and status disparities characterize these relationships, with the protégé(e) typically having less of these attributes. ${ }^{38}$

\section{THE BENEFITS OF MENTORING}

In the best of circumstances, the process of mentoring is mutually beneficial to both mentors and protégé(e)s in ways that include personal and career growth. Mentors often find themselves professionally stimulated, personally enriched and perhaps rejuvenated, and, as proposed by Erickson, ${ }^{39}$ derive satisfaction from this activity during the developmental stage of generativity. Similarly, Levinson et al. ${ }^{29}$ recognized mentoring as a developmental life stage, a time in which seasoned professionals give back to their professions. Those who are mentored are likely to continue the legacy of mentoring with their own students and junior colleagues. $38,40,10$

\section{THE RISKS OF MENTORING}

Mentoring is often assumed to be a universally positive experience for mentors and protégé(e)s, ${ }^{41}$ with benefits outweighing risks in most mentoring relationships, ${ }^{11}$ whether formal or informal. Both mentor and protégé(e), however, are said to take risks when engaged in mentoring. ${ }^{42}$ Mentors and their protégé(e)s, for example, may hold disparate goals, levels of commitment, and expectations of mentoring. Protégé(e)s may have unrealistic expectations, may make unreasonable demands of their mentors, or may be unreceptive to mentoring. Senior faculty who are pressured into becoming mentors may be disinterested and unhelpful to the protégé(e)s assigned to them. ${ }^{43}$ Of concern are relationships that are "entrenched with power issues, ${ }^{41,44}$ generational tensions, ${ }^{42}$ and personality clashes. Within the context of mentoring lies the potential for mentors to perpetrate the status quo; foster overdependency ${ }^{9}$; fail to recognize and address the protégé(e)'s career goals, personal values, and needs; and provide inappropriate advice and misuse power. ${ }^{43,45}$ Protégé(e)s may evolve into "clones" of their mentors ${ }^{11}$ rather than developing their own professional identity. They may also experience a mentor's inaccessibility, desertion, or exploitation, ${ }^{45}$ as exemplified by a mentor who usurps a protégé(e)'s work, pressures a disinterested protégé(e) to continue involvement in the mentor's research, ${ }^{46}$ or inappropriately demands authorship. Individuals may also experience unwanted romantic interest, ${ }^{47}$ sexual harassment, ${ }^{13}$ or other inappropriate behavior. Both mentor and protégé(e) may experience negative feelings if or when one or the other chooses to terminate the relationship. ${ }^{48}$

\section{LESSONS LEARNED FROM OBSERVING MENTORING PROGRAMS}

In 1998, we were funded by the U.S. Department of Health and Human Services Office on Women's Health (OWH) as a National Center of Leadership in Academic Medicine, charged with developing model mentoring programs for faculty with the goals of career advancement of junior faculty and gender equity in academic medicine. ${ }^{36}$ We designed, implemented, and evaluated 2 different model mentoring programs ${ }^{49}$ and a mentor training program, and had the opportunity to study carefully how medical faculty experienced the mentoring process. In this paper, brief reports of the dyadic program and Collaborative Mentoring Program (CMP) are offered; a detailed description and evaluation of the CMP has been published. ${ }^{12}$

\section{The Dyadic Mentoring Program}

The formal dyadic Personal Mentoring Program (PMP) paired a junior faculty member with a senior faculty mentor in a one-toone mentoring relationship for 2 years. The matching of protégé(e) and mentor was based on protégé(e) preferences. The mentor-protégé(e) dyads were expected to meet for an hour at least monthly during a 2-year period and maintain communication with one another via e-mail. Concurrently, mentors voluntarily engaged in a Mentoring Skills Program that provided them with skill development workshops, materials to use with their protégé(e)s, and opportunities to process their mentoring experiences with one another.

Consistent with observations from other formal dyadic mentoring programs, outcomes of the PMP program varied considerably. Qualitative program evaluation data revealed that protégé(e)s held a complexity of both positive and negative views about their mentorship experiences. Positive outcomes reported by some protégé(e)s suggested that at least some mentors approached Bhagia and Tinsley's ${ }^{31}$ ideal: someone who inspires, supports, and invests in the protégé(e) while providing psychosocial and career support. Other protégé(e)s, however, characterized mentorship as "superficial," "exploitive," "mediocre," or "nonexistent." Four of 11 participants reported that they were not able to establish and maintain a positive one-to-one relationship for 2 years with their mentor.

Protégé(e)s and mentors in the formal program cited finding time for mentoring as a persistent and serious difficulty despite their voluntary enrollment in the program. An inability to find time to meet for 1 hour each month raises questions about the nature of the mentoring relationship and protégé(e)s' 
continuing uncertainty about its helpfulness and value. As Jackson et al. ${ }^{13}$ suggest, effective mentoring requires "a certain chemistry" between those involved. Although some protégé(e)s embraced their mentoring relationships and almost all were able to derive some benefit from the experience, several protégé(e)s acknowledged that their mentoring relationship felt forced and artificial, primarily as a consequence of, in the words of one protégé(e), "taking 2 people and sticking them together."

\section{Collaborative Monitoring Program}

The $\mathrm{CMP}^{12}$ provided a facilitated group peer mentoring experience and skill development for junior faculty over an 8month period. Beginning with an intensive 3-day session, the protégé(e)s continued together for 6 monthly day-long sessions. The program was structured as follows: (1) formulation of an academic development plan, (2) skills development in areas essential for advancement in academic medicine, and (3) a scholarly writing program. ${ }^{50}$

The group was facilitated by the program director (L. P.), with the involvement of an additional cofacilitator for some of the sessions. The role of the facilitator was to ensure a safe and respectful learning environment, foster peer collaboration, and redirect the group to draw upon their own experiences and reactions to address each other's needs and concerns. This was in contrast to more traditional mentoring practices where mentors typically share personal solutions or experience and offer advice. In the CMP program, participants came to recognize, value, and ultimately rely upon the wisdom and diverse expertise of their peers. Whereas the PMP was modeled on the familiar dyadic framework of mentoring, the CMP course was modeled on adult learning theory, ${ }^{51,52}$ theories of adult development, ${ }^{29,39}$ the concepts of Carl Rogers, ${ }^{53}$ Friere's concept of "praxis," 54 and on theory related to small-group dynamics. ${ }^{55}$

CMP evaluation data ${ }^{12}$ highlighted the critical nature of a supportive learning environment. Learning outcomes included the following: (1) identification of their own core values; (2) the identification of short- and long-term career goals based on these core values; (3) the development of close collaborative relationships; (4) skill development; and (5) improved job satisfaction linked in part to their decision to remain in academic medicine. Participants described a sense of empowerment and personal transformation. Program attendance was excellent (89\%), in contrast to the insuperable scheduling difficulties reported in the PMP.

\section{PERSPECTIVE}

Given the potential that effective mentoring has for facilitating career and personal success and satisfaction, the inadequate numbers of "informal" mentoring opportunities, the difficulties of implementing widespread effective formal mentoring programs, and the drawbacks and unpredictability of formal dyadic mentoring we propose a reconsideration of traditionally held views of mentoring. We seek additional mentoring models for medical faculty that can predictability and effectively meet the needs of diverse faculty groups. Our perspectives on mentoring are based on the research literature and on what we have learned through observing and documenting mentoring outcomes. Although long-term outcomes are not yet available, findings from the projects described here briefly contribute to a reenvisioning of the scope and structure of the mentoring process.

Everyone can benefit from mentoring in important ways, regardless of status, position, or level of expertise. The most beneficial forms of mentoring arise in the context of positive relationships and the creation of trustworthy, nurturing environments that facilitate learning and the open expression of personal concerns. It is within these environments that individuals can engage in identifying and addressing their core values, priorities, and learning needs. Additionally, mentoring may be particularly critical for the success and advancement of those less likely to be included in senior and leadership roles such as women and underrepresented minority faculty members. ${ }^{35}$ These nontraditional groups may be better served by nontraditional mentoring models.

Designing mentoring programs based on strategies and attributes that are known to facilitate relationship building and personal empowerment, that include structured experiential learning for skill development, and that draw on the richness of groups of individuals working collaboratively has great potential to more reliably and effectively meet the needs of faculty in academic medicine. Formal peer group mentoring reliably supports enhanced relationship development, avoids the misuse of power, compensates for the dearth of appropriately trained and willing senior mentors, and provides process and mentoring training.

We concur with Daloz that the many limitations associated with traditional mentoring are related to a failure of the mentoring dyad to move beyond an initially hierarchical relationship to one that is more egalitarian and complementary. ${ }^{56}$ The implied superior knowledge of mentors may be disempowering and restrictive for protégé(e)s, and less satisfying for mentors. The equalization of power in peer mentoring parallels relationships between physicians and patients in patientcentered practice, ${ }^{57}$ and between teachers and learners in learner-centered education. ${ }^{58}$

Consistent with Erickson's developmental stage of generativity, ${ }^{39}$ a worthy imperative for mentoring often emanates from faculty. Senior-level faculty may have a tendency to discount collaborative group peer mentoring models for junior faculty as these do not reflect their own altruistic motivations to mentor. Ideally, we need a structure that honors the altruism of senior faculty and utilizes the benefits and opportunities that this experienced group can offer. Such a structure could serve in conjunction with collaborative peer group efforts. In addition, the needs of senior faculty are not frequently addressed. In the context of the mentor training program implemented, for example, we found that senior faculty identified their own peer group experience as the most valued outcome of their training in mentoring.

Facilitated peer group mentoring offers significant benefits to participants, including empowerment; an absence of power differential; the involvement of multiple areas of expertise; mutuality; training for mentoring; and the development of personal awareness. We observed the program's positive impact on collegiality and sense of belonging in a medical school, faculty retention, contributions to institutional goals, and the subsequent assumption of leadership roles by faculty participants. Because of the promise that this mentoring process holds, further research and evaluation of group peer mentoring in academic medicine is needed. An expanded vision of mentoring as a collaborative peer group process does not ne- 
gate or diminish the value of informal dyadic mentoring; rather, it adds another dimension to the mentoring process and one that provides an effective, accessible mentoring opportunity for all faculty, as they strive to achieve their professional goals.

Mentoring programs in academia must more effectively address institutional and departmental needs for faculty retention and success; provide for the needs of diverse persons; address the issue of having very few senior faculty, both men and women, to mentor junior faculty; and extend the benefit of mentoring to midlevel and senior faculty members. Effective mentoring programs may be instrumental in addressing not only professional development needs but may also result in reduced burnout and increased physician retention. Such programs serve as a means of promoting physician well-being ${ }^{21}$ and contributing to physicians' ability to fulfill their life dreams.

We thank all the faculty participants who volunteered for our demonstration programs and from whom we have learned so much. We are also grateful to Drs. Saralyn Mark and Wanda Jones of the Office on Women's Health (OWH), U.S. Department of Health and Human Services (DHHS), for their encouragement and strong support of mentoring programs, and to the U.S. DHHS, OWH (contract number: 282980051) for funding us as 1 of the 4 National Centers of Leadership in Academic Medicine, a 3-year project on which our work is based.

\section{REFERENCES}

1. Ramanan R, Phillips R, Davis RB, Silen W, Reede J. Mentoring in medicine: keys to satisfaction. Am J Med. 2002;112:336-41.

2. Beier SR, Rosenfeld WD, Spitalny KC, Znasky SM, Bontempo AN. The potential role of an adult mentor in influencing high-risk behaviors in adolescents. Arch Pediatric Adolesc Med. 2000;154:327-31.

3. Healy CC, Welchert AJ. Mentoring relations: a definition to advance research and practice. Educ Res. 1990;19:17-21.

4. Kram KE. Improving the mentoring process. Training Dev J. 1985; 39:40-3.

5. Longhurst MF. The mentoring experience. Med Teacher. 1994;16: 53-9.

6. Kalet A, Krackov S, Rey M. Mentoring for a new era. Acad Med. 2002;77:1171-2.

7. Rabatin JS, Lipkin M, Rubin AS, Schacter A, Nathan M, Kalet A. A year of mentoring in academic medicine. Case report and qualitative analysis of fifteen hours of meetings between a junior and senior faculty member. J Gen Intern Med. 2004;19:569-73.

8. Palepu A, Friedman RH, Barnett RC, et al. Junior faculty members' mentoring relationships and their professional development in US medical schools. Acad Med. 1998;73:318-23.

9. Stange KC, Heckelman FP. Mentoring needs and family medicine faculty. Fam Med. 1990;22:183-5.

10. Morzinski JA, Diehr S, Bower DJ, Simpson DE. A descriptive, crosssectional study of formal mentoring for faculty. Fam Med. 1996;28: 434-8.

11. Rogers JC, Holloway RL, Miller SM. Academic mentoring and family medicine's research productivity. Fam Med. 1990;22:186-90.

12. Pololi LH, Knight SM, Dennis K, Frankel RM. Helping medical school faculty realize their dreams: an innovative collaborative mentoring program. Acad Med. 2002;77:377-83.

13. Jackson VA, Palepu A, Szalacha L, Caswell C, Carr PL, Inui T. "Having the right chemistry: a qualitative study of mentoring in academic medicine. Acad Med. 2003;78:328-34.

14. Woods SE, Reid A, Arndt JE, Curtis P, Stritter FT. Collegial networking and faculty vitality. Fam Med. 1997;29:45-9.

15. Cadman EC. The academic physician-investigator: a crisis not to be ignored. Ann Intern Med. 1994;120:401-10.

16. Illes J, Glover GH, Wexler L, Leung AN, Glazer GM. A model for faculty mentoring in academic radiology. Acad Radiol. 2000;7:959.
17. Edwards K. "Short stops": peer support of scholarly activity. Acad Med. 2002;77:9.

18. Bligh J. Mentoring: an invisible support network. Med Educ. 1999; 33:2-3.

19. SCOPME An Enquiry into Mentoring: Supporting Doctors and Dentists at Work. London, UK: Standing Committee on Postgraduate Medical and Dental Education; 1998.

20. Kohrs FP, Mainous AG. Retention of family medicine faculty development fellows in academic medicine. Fam Med. 1999;30:23-7.

21. Shanafelt TD, Sloan JA, Habermann TM. The well-being of physicians. Am J Med. 2003; 114:513-9.

22. Deckard GJ, Hicks L1, Hamory BH. The occurrence and distribution of burnout among infectious disease physicians. J Infect Dis. 1992;165: 224-8.

23. Whippen DA, Canellos GP. Burnout syndrome in the practice of oncology: results of a random survey of 1000 oncologists. J Clin Oncol. 1991;9:1916-20.

24. Dunnington GL. The art of mentoring. Am J Surg. 1996;171:605-7.

25. Setness PA. Mentoring: leaving a legacy of opportunity and responsibility. Postgrad Med. 1996;100:15-22.

26. Benjamin JB. Mentoring and the art of medicine. J Trauma. 1998;45: 857-61.

27. Nathan DG. Clinical research: perceptions, reality, and proposed solutions. JAMA. 1998;280:1427-31.

28. Morzinski JA, Simpson DE, Bower DJ, Diehr S. Faculty development through formal mentoring. Acad Med. 1994;69:267-9.

29. Levinson D, Darrow C, Klein E, Levinson M, McKee B. The Seasons of a Man's Life. New York, NY: Knopf; 1978.

30. Lagay F. If role models do model roles. Am Med Assoc J Dis. 2002. Available at: http://www.ama-assn.org/ama/pub/category/9145.html. Accessed June 10, 2005.

31. Bhagia J, Tinsley JA. The mentoring partnership. Mayo Clin Proc. 2000;75:535-7.

32. Ellinger AD. Mentoring in contexts: the workplace and educational institutions. In: Hansman C, Mott V, Ellinger AD, Guy T, eds. Critical Perspectives on Mentoring: Trends and Issues. Eric Info Series No. 388. Ohio, Japan: ERIC Clearinghouse on adult, career, and vocational education, Ohio State University; 2002:39-48.

33. Goodwin LD, Stevens EA, Bellamy GT. Mentoring among faculty in schools, colleges, and departments of education. J Teacher Educ. 1998; 49:334-43.

34. Mott v. Emerging perspectives on mentoring: fostering adult learning and development. In: Hansman C, Mott V, Ellinger AD, Guy T, eds. Critical Perspectives on Mentoring: Trends and Issues. Eric Info Series No. 388. Ohio, Japan: ERIC Clearinghouse on adult, career, and vocational education, Ohio State University; 2002:15-26.

35. Bickel J, Wara D, Atkinson BF, et al. Increasing women's leadership in academic medicine: report of the AAMC Project Implementation Committee. Acad Med. 2002;77:1043-61.

36. Mark S, Link H, Morahan P, Pololi L, Reznik V, Tropez-Sims S. Innovative mentoring programs to promote gender equity in academic medicine. Acad Med. 2001;76:39-42.

37. US Public Health Service's Office on Women's Health Recommendations for a Successful Mentoring Program. US PHS 1998 RFP 282-98-0034 Attachment A.

38. Trunnell EP, Grosshans O, Ransdell L. Introducing a mentoring framework for university faculty. Health Educ Monogr Ser. 2003;20: $6-10$.

39. Erikson EH. The Life Cycle Completed: A Review. New York, NY: Norton; 1982.

40. Vaillant G. Adaptation to Life. New York: Little Brown \& Co; 1977.

41. Hansman CA. Diversity and power in mentoring relationships. In: Hansman C, Mott V, Ellinger AD, Guy T, eds. Critical Perspectives on Mentoring: Trends and Issues. Eric Info Series No. 388. Ohio, Japan: ERIC Clearinghouse on adult, career, and vocational education, Ohio State University; 2002:39-48.

42. Greene MT, Puetzer M. The value of mentoring: a strategic approach to retention and recruitment. J Nurs Care Qual. 2002;17:63-70.

43. Hansman CA. Looking forward: implications for practice and suggestions for future research. In: Hansman C, Mott V, Ellinger AD, Guy T, eds. Critical Perspectives on Mentoring: Trends and Issues. Eric Info Series No. 388. Ohio, Japan: ERIC Clearinghouse on adult, career, and vocational education, Ohio State University; 2002:49-52.

44. Freeman R. Faculty mentoring programs. Med Educ. 2000;34:507-8.

45. Bilinski H. The mentored journal. Nurs Educator. 2002;27:37-41. 
46. Mainous AG. The importance of track records in developing family medicine research. Fam Med. 2003;35:138-40.

47. Darwin A. Critical reflections on mentoring in work settings. Adult Educ Q. 2000;50:197-211.

48. Kram KE. Phases of the mentoring relationship. In: Mentoring at Work. Developmental Relationships in Organizational Life. Glenview, Ill: Scott Foresman and Co; 1985.

49. Pololi L. National Center for Leadership in Academic Medicine at East Carolina University. Final Technical Report, September 2000. Contract number: 282-98-0052 US PHS Office on Women's Health.

50. Pololi L, Knight S. Facilitating scholarly writing in academic medicine: lessons learned from a collaborative peer mentoring program. J Gen Intern Med. 2004;19:64-8.

51. Knowles MS. The Modern Practice of Adult Education: from Pedagogy to Andragogy. New York, NY: Continuum; 1986.
52. Brookfield SD. Understanding and Facilitating Adult Learning. San Francisco, Calif: Jossey-Bass; 1987.

53. Rogers CR. The facilitation of significant learning. In: Siegel L, ed. Instructions: Some Contemporary Viewpoints. San Francisco, Calif: Chandler; 1967:37-54.

54. Freire P. Pedagogy of the Oppressed. New York, NY: Continuum; 1986.

55. Tuchman BW. Developmental sequence in small groups. Psychol Bull. 1965;63:384-99.

56. Daloz L. Effective Teaching and Mentoring: Realizing the Transformational Power of Adult Learning Experience. San Francisco, Calif: JosseyBass; 1996.

57. Paice E, Heard S, Moss F. How important are role models in making good doctors? BMJ. 2002;325:707-10.

58. Pololi L, Clay MC, Lipkin M, Hewson M, Kaplan C, Frankel RM. Reflections on integrating theories of adult education into a medical school faculty development course. Med Teacher. 2001;23:276-83. 